\title{
Compreensão das mudanças comportamentais do usuário no Programa Saúde da Família por meio da participação habilitadora
}

\author{
Understanding the user's health behavior change \\ through their participation in the Family Health Program
}

M aria de Fátima Antero Sousa M achado ${ }^{1}$

Neiva Francenely Cunha Vieira ${ }^{2}$

Raimunda M agalhães da Silva ${ }^{3}$

\footnotetext{
${ }^{1}$ Departamento deSaúde, Centro de Ciências da Saúde, U niversidade Regional do Cariri. RuaCel. Antonio Luis 1.161, Pimenta. 63105-000 Crato CE.

fatimaantero@uol.com.br

${ }^{2}$ Departamento de

Enfermagem, Universidade

Federal do Ceará.

${ }^{3}$ Centro deCiências da

Saúde/M estrado em Saúde

Coletiva, Universidade de

Fortaleza.
}

Abstract This study aimed to understand how users from Family Health Program (FHP) make their decision about health-illness. It was used the Stages of Change M odel from Prochaska and DiClementeto identify the level of change of FH P users. It was a qualitative research developed with users and FHP health professionals from Crato, Ceará State, Brazil. The data were collected by semi-structured interviews, focal group and observation from M ay to September in 2005. They were organized by means of content analysis and analyzed in the light of theoretical reference. The changes of the FHP users are depicted as following: in the pre-contemplation stage the emphasis is on di sease and care itself. In the contemplation stage, the care is on the family. It is centred in the cureand treatment of diseases. In the determination stage, we have some improvement concerning prevention in thefamily, with registers of looking around. In the action stage, behaviour from the user to reach autonomy and emancipation is registered. These results seem to indicate ascendency in FHP users' learning and participation towards health promotion. Key words $\mathrm{H}$ ealth promotion, Health education, Community participation, Family H ealth Program, Public health nursing
Resumo Esteestudo objetivou compreender como ocorrem os processos decisórios da participação dos usuários no Programa Saúde da Família (PSF), relacionados à saúde-doença, identificando neste movimento o nível de mudança do usuário a partir do modelo de estágio de mudança, de Prochaska e DiClemente. Estudo qualitativo, desenvolvido com usuários do PSF e profissionais das Equipes Saúde da Família, do município do Crato, Ceará, Brasil. Os dados foram coletados por meio da entrevista semiestruturada, grupo focal e observação, no período de maio a setembro de2005, organizados medianteanálise de conteúdo e analisados à luz do referencial teórico. As mudanças do usuário no PSF estão assim configuradas: na fase de précontemplação, a ênfase é na doença, no cuidado desi . $\mathrm{N}$ a de contem plação, o cuidado é na família, centrado na cura e tratamento da doença. $\mathrm{Na}$ fase de determinação, há avanço no sentido da prevenção na família, com registros de olhar no entorno. $\mathrm{Na}$ de ação, já se registra um comportamento do usuário para alcançar sua autonomia e emancipação. Estes re sultados parecem indicar ascendência na aprendizagem de participação do usuário no PSF em direção à promoção da saúde.

Palavras-chave Promoção da saúde, Educação em saúde, Participação comunitária, Programa Saúde da Família, Enfermagem em saúde pública 
Introdução

O Informe Lalonde, de 1974, é tido como um referencial histórico no campo da saúde pública erepresentou um marco na disseminação do ideário da promoção da saúde. A mudança de enfoque da atenção tradicionalmente curativa para uma abordagem preventiva começava a se delinear, iniciando-se a construção de um conceito de saúde e se estabelecendo a meta "Saúde para todos atéo ano 2000". Uma compreensão de saúde que transcende aos determinantes biológicos do processo de ser saudável. Incorpora a dinâmica da vida cotidiana das pessoas, valorizando o trabalho, transporte, moradia elazer. Em 1986, a Reunião Internacional de Saúde, em Ottawa, Canadá, retomou e absorveu o sentido e as de terminações de Alma-Ata, formalizando uma declaração de princípios que demanda uma nova visão em saúde pública ${ }^{1}$.

A Carta de Ottawa conceitua promoção da saúde como um processo de capacitação da comunidade para atuar na melhoria da sua qualidade de vida e saúde, incluindo uma maior participação no controledesseprocesso 2 . Diantedeste conceito, podemos imaginar o quanto é importante a educação para que haja uma mudança na forma de pensar e agir das pessoas e, consequentemente, uma melhoria na sua qualidade devida.

A transformação, portanto, do modelo assistencial curativo em um padrão voltado para a atenção primária se fazia necessária para se adequar ao novo conceito de saúde que se esboçava então. Somente nos anos seguintes, as discussões se intensificaram e as conferências sobre promoção de saúde realizadas em Ottawa, Sundswall, Adelaide e Jacarta tiveram papel fundamental, pois retificaram a participação dos grupos coletivos nas ações para a promoção da saúde como um instrumento de desenvolvimento de políticas públicas saudáveis, fortalecendo as ações comunitárias e habilidades pessoais.

$\mathrm{Na}$ ideia de promoção da saúde como um "novo modelo" de saúde, centrado na promoção da qualidade de vida e formulado a partir dos princípios do SistemaÚ nico deSaúde(SUS), tais como universalidade, integralidade, descentralização e participação da comunidade, surge o Programa Saúde da Família (PSF), instituído pelo Ministério da Saúde.

O PSF é uma estratégia política que vem ao longo dos anos de implantação eimplementação contribuindo para a diminuição das iniquidades, sobretudo a ampliação do acesso aos serviços básicos de saúde e a vinculação das equipes junto aos indivíduos, famílias e comunidades, na complexa tarefa de cuidar da vida, doença, sofrimento e morte 3 . Um ponto a se destacar nesta estratégia é o foco na família, considerando-a como sujeito de atenção, sobre o qual se deveter pleno conhecimento dos problemas, o que exige uma nova abordagem para os profissionais de saúde e uma interação qualificada da equipe de saúde, ou seja, uma orientação dos serviços para as comunidades nas quais as famílias habitam ${ }^{4}$.

A promoção da saúde como um processo articulado com a produção da saúde requer um esforço e exercício coletivo para o desenvolvimento de estratégias de educação em saúde que viabilizem e incorporem práticas saudáveis e habilidades por parte do usuário como elemento de concretude dessa proposta, numa perspectiva democrática e valorizando a inserção dos membros da sociedade como seres ativos, autônomos e participativos.

Educação em saúde é um processo que, ao fazer uso da comunicação, busca conferir às pessoas conhecimentos e aptidões para que estas possam fazer escolhas sobre sua saúde, despertando a consciência crítica, reconhecendo os fatores que influenciam a saúde e encorajando-as a fazer algo para mudar o status quo, com base na interação respeitosa da cultura popular, em oposição à prática comumente adotada através do autoritarismo paternalista que faz da educação em saúde muitas vezes um fracasso.

O desenvolvimento dehabilidades favoráveis à saúde acontece em decorrência da divulgação de informações e da educação em saúde, em todos os espaços coletivos, preparando o indivíduo para as diversas fases da existência e 0 enfrentamento das enfermidades ${ }^{5}$. N este contexto, se insere a ideia de empowerment, ou seja, a aquisição de poder técnico (capacitação) e político pelos indivíduos e pela comunidade. 0 poder e controle das pessoas sobre o seu destino produzem ações concretas e efetivas na tomada de decisão para 0 atendimento das prioridades, na definição de estratégias e na sua implementação visando à melhoria das condições de saúde.

Entretanto, acreditamosquea mudança consciente ocorre com a participação efetiva do usuário/família nos meios de produção de conhecimentos e de habilidades para agir na promoção da saúde, ou seja, o quenesteestudo construímos e definimos como participação habilitadora. Este tipo de participação é entendida como um processo consciente, crítico, em que a mudança de comportamento para cuidar da saúde se dá pela aprendizagem sobre saúde, pelas habilidades 
aprendidas, pelo entendimento das condições de saúde articuladas ao estilo de vida e como os serviços de saúde operam. A partir deste entendimento, o usuário terá de fato vivido uma participação habilitadora, no sentido de ser uma mudança consciente, sendo capaz de mudar, mudar na família e mudar o contexto em que vive.

A participação acontece quando as ações são planejadas em conjunto eo papel de cada pessoa envolvida é definido para a realização das ações, ou seja, as pessoas são autoras do processo $0^{6}$. Entendemosque 0 ato deeducar em saúdesedar quando o usuário/família/comunidade participa do seu próprio destino no que se refere à saúde, tornando-se sujeito ativo e autônomo a fim de desenvolver uma consciência crítica reflexivae uma ação participativa na busca de soluções para uma prática mais eficaz.

Desta forma, a participação deve ser incorporada no cenário do Programa Saúde da Família, por fazer parte da própria filosofia do programae, no momento quedesloca o eixo do atendimento da unidade para o contexto familiar, 0 cliente usuário não mais visita o serviço e sim passa a ser visitado pelos profissionais de saúde no locus familiar. Este deslocamento do atendimento para o domicílio representa uma mudança de contexto, possibilitando o rompimento das barreiras que entravam a formação do vínculo, tão importante para criação de um ambiente de aproximação e confiança do usuário com o profissional, inibindo, assim, os elementos opositores à participação, como, por exemplo, a autoridade do profissional sobre o usuário.

Estas inquietações e reflexões apresentadas até aqui nos auxiliaram na construção deste estudo desenvolvido junto ao Programa Saúde da Família, no qual se buscou compreender como ocorrem os processos decisórios da participação habilitadora dos usuários no PSF, relacionados à saúde-doença, identificando nestemovimento o nível de mudança do usuário, a partir do modelo de estágiosdemudança, de ProchaskaeDiClemente.

\section{Metodologia}

Trata-se de uma pesquisa qualitativa, na qual utilizamos o modelo de estágios de mudança de Prochaska e DiClemente como referencial teórico metodológico de investigação.

0 modelo de estágios de mudança foi desenvolvido em 1982, sendo resultado do estudo comparativo de teorias de psicoterapia e de mudança decomportamento. Descreve explica diferentes estágios comuns que ocorrem com as pessoas durante os processos de mudança. Baseia-se no fato dequea mudan ça de comportamento é processual e que os indivíduos têm vários níveis de motivação e prontidão para mudar ${ }^{7,8}$.

Prochaska e DiClemente ${ }^{9}$ descrevem a prontidão para mudar como estágios de mudança pelos quais o individuo transita. Ao desenvolverem um instrumento para identificar os estágios de mudança, chegaram a quatro estágios bem definidos, confiáveis ebem relacionados entresi: pré contemplação, contemplação, determinação ou preparação e ação. Os autores trazem ainda o estágio denominado manutenção, que identificam como etapa de manutenção. Este modelo, segundo seus autores, tem como núcleo a proposta educativa centrada no processo demudança de comportamento individual para a saúde.

0 modelo de estágios de mudança de Prochaska e DiClemente inspirou a construção da estrutura teórica do estudo, denominada de estrutura teórica de uma participação habilitadora. Buscamos, a partir deste construto, identificar níveis de mudanças ocorridos nos indivíduos e família ao longo de sua incorporação no PSF. Tomamos como descritor de evidênciacomportamentos e atitudes manifestados e/ou relatados pelos informantes como resultado de sua participação no processo de educação em saúde.

A Figura 1 traz a estrutura teórica de uma participação habilitadora a partir do modelo de estágios de mudança.

A participação habilitadora, entendida no estudo, como já mencionado, como um processo que leva à autonomia e emancipação do usuário, construída por meio de um processo educativo, pode acontecer em diferentes níveis dentro do Programa Saúde da Família. Acreditamos que este processo acontece em movimento espiral ascendente, como demonstrado na Figura 1, ocorrendo por meio do estímulo à participação do usuário para o desenvolvimento de conhecimentos e habilidades para agir na promoção da saúde, no sentido do mais simples para o de maior complexidade. No primeiro nível, o indivíduo aprende a cuidar de si mesmo; no segundo, aprende a cuidar do contexto da família; no terceiro, aprende a ol har o entorno e, por último, aprende a exercer a cidadania.

Conforme a Figura 1, trazemos na primeira coluna os níveis de participação presentes nas ações de promoção da saúde pelas Equipes de Saúde da Família (ESF); nos círculos, os descritores que tratam do processo de mudança presente nas narrativas; na segunda coluna, os tipos 


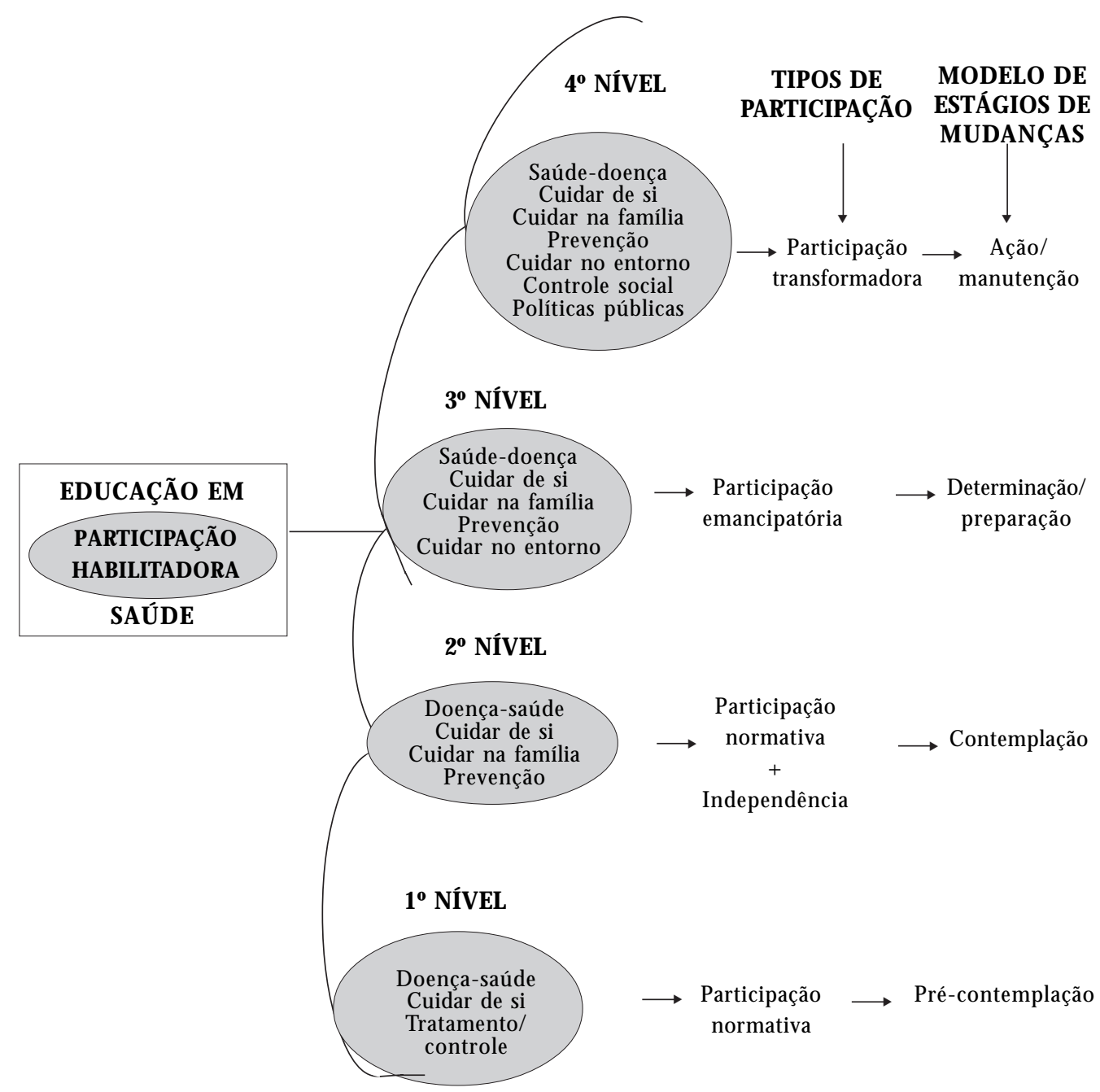

Figura 1. Estrutura teórico-metodológica de uma participação habilitadora. Fortaleza (CE), 2006.

de participação e, na terceira coluna, a partir da relação das anteriores, em que estágio de mudança se encontra o usuário dentro do Programa Saúde da Família. Este construto teórico está estruturado em forma de espiral, como já mencionado, por entendermos que o usuário pode ser reconhecido em qualquer um dos níveis, sinalizando para os profissionais de saúde a necessidade de ações para a promoção de uma participação transformadora/ação/manutenção.

Acreditamos que o modelo escolhido guiou a busca pela compreensão do nosso objeto de investigação, no sentido de nos apontar, por meio dos estágios de mudança, qual a direção político-ideológica que o movimento educativo do Programa Saúde da Família conduz quanto à participação do usuário.

A pesquisafoi desenvolvida na cidade do Crato (CE). $O$ serviço de atenção primária a saúde está focalizado nas Unidades Básicas com Programa Saúde da Família eencontra-sehojecom 24 equipes, distribuídas da seguinte forma: catorze na zona urbana e dez na zona rural. N esse cenário, selecionamos, para a investigação, as equipes sediadas na zona urbana; dentre essas, aquelas que no momento da coleta dos dados esti vessem com 
mais de cinco anos de implantação, levando em conta a vivência dos usuários no programa, totalizando cinco ESF investigadas.

0 grupo de informantes foi composto por 42 usuários e 32 profissionais das cinco equipes do PSF selecionada, perfazendo um total de 73 informantes para a pesquisa. Os usuários entrevistados foram aqueles com mais de cinco anos no programa e que concordaram espontaneamente em participar do estudo. Os profissionais entrevistados representaram a totalidade dos profissionais inseridos nas cinco ESF do estudo.

A coleta de dados foi orientada por três instrumentos que, apesar de distintos, se comple tam nas suas funções de busca de informações, permitindo níveis distintos de eficácia no processo de coleta de dados. Assim, utilizamos a entre vista semiestruturada, o grupo focal e a observação. A utilização desses instrumentos possibilitou a técnica de triangulação dos dados, a qual representa na pesquisa um recurso de rigor metodológico, pois permite analisar o objeto de estudo usando mais de uma visão.

Optamos como procedimento de organização de dados o método de análise de conteúdo, 0 qual orientou a construção das categorias, as quais foram inspiradas nos objetivos, nos depoimentos e no referencial teórico do estudo. Estas categorias formaram o mapa conceitual de análise, o qual indicou a direção política ideológica do tipo de participação promovido pela ESF aos usuários do PSF.

A análise dos dados foi submetida à luz do referencial teórico e da literatura para a pesquisa, nos eixos da promoção da saúde, educação em saúde, partici pação e Programa Saúde da Família. 0 projeto foi aprovado sob Parecer $n^{\circ} 86 / 05$ pelo Comitê de Ética do Complexo Hospitalar da Universidade Federal do Ceará (COM EPE), cumprindo a Resolução n $196 / 96^{10}$.

\section{Resultados}

Níveis de mudança dos usuários no Programa Saúde da Família

Conforme a estrutura teórico-metodológica da participação habilitadora elaborada no estudo, foram definidos níveis de participação. Para cada nível, foram definidos descritores que caracterizam fases de mudanças dos usuários no PSF. Buscamos nos depoimentos dos informantes identificá-los e, assim, constituir nosso corpus descritivo para análise.
Primeiro nível:

participação normativa -pré-contemplação

Foi considerada uma participação normativa quando nas falas dos informantes foram encontrados descritores que expressem ações com predominância nos seguintes temas: doença-saúde; cuidar de si; tratamento/controle.

Os usuários expressaram nas suas falas evidências deque sua participação no programa está condicionada à doença, mais especificamente a sua doença, com expressão de prontidão para adotar mudança no cuidado de si a partir da doença instalada com ênfase na prevenção.

Foi um tratamento de enfraquecimento que 0 povo chama tuberculoso, foi esse momento que eu vim pra cá. (U-1.3)

Eu procurei o PSF porque eu tiveum problema na pressão, desde essa época que eu entrei em tratamento com o doutor aqui do posto. (U-1.7)

Eu descobri que eu tinha problema, eu era hipertensa etinha problema de coração, então eu fui pro médico e fui atendida, a partir daí frequento 0 PSF. (U-2.2)

Eu venho pra cá porque sou cardíaca, doente do coração, sou portadora também de brucel ose e, além do coração, tem a pressão alta. (U-5.2)

As falas dos usuários refletem uma participação do tipo normativa ou pré contemplativa, na qual o usuário tem o conhecimento de que tem a doença, tem uma prontidão para adotar uma mudança em resposta a esta doença, mas ainda não adotou mudança de comportamento em saúde fora desta condição. Esse modo como o usuário busca o programa ainda reflete o modelo tradicional, no qual a assistência era centrada na doença e no individuo.

No estudo deVázquez et al. ${ }^{11}$, há uma predominância de idéias centradas na partici pação referente à utilização dos serviços de saúde. Segundo esses autores, numerosos entrevistados descreveram a participação como a utilização dos serviços de saúde, isto é, a oportunidade de beneficiar-se das atividades e programas oferecidos pelas unidades de saúde, a oportunidade de utilizá-los quando for necessário, quando da sua doença.

Arstein ${ }^{12}$ classifica o processo participativo denominado escala de participação de Arstein em dois grandes níveis. 0 primeiro nível é chamado de participação simbólica e inclui categorias que se caracterizam pela falta de partilha de poder e considera participar como a utilização de serviços de saúde, acesso à informação eatendimento a benefícios, como, por exemplo, a consulta. 0 segundo nível, denominado controleci- 
dadão, começa com a colaboração, inclui o poder delegado e, finalmente, alcança um grau denominado controle cidadão. 0 comportamento evidenciado no usuário desteestudo está de acordo com o primeiro nível da escala de Arstein.

Em um estudo realizado no Rio de Janeiro, com osusuários da redepública, viu-seque, quando se trata de participação em saúde, o que mais se evidencia é 0 enfrentamento da população na tentativa de solucionar seus problemas de saúde no cotidiano. Participar tem como principal objetivo ser ben eficiado pela assistência e, para esses usuários, o mais importante é ser atendido ${ }^{13}$.

Os profissionais confirmam estenível departicipação encontrada, destacando o valor conferido pelo usuário à consulta e medicamentos eà atenção individualizada.

A comunidade vem atrás de remédio, vem por causa da doença, a parte educativa sanitária eles não valorizam, mesmo porque ela não tem ensinamento pra isso. ( $M$ édico 1 )

0 atendimento ainda é muito particularizado, vocênão consegue integrar o usuário no ambiente familiar ondeele está, a gentefaz ainda uma medicina fragmentada, ainda baseada naqueles conceitos mais antigos de medicina. ( $M$ édico 2 )

Eles procuram o PSF pela doença, pelo proble ma, principalmente o profissional médico. (Enfermeira 1)

É mais pela doença, é claro, e eles já são viciados por medicamento. (ACS 3.1)

Quando elesvêm ao médico, épor causa daqueles problemas, daquela mancha, pra verificar a pressão, eles procuram é porque estão precisando, a participação deleséa necessidadedecada um. (Aux. Enf. 4)

Asfal as dos profissionais são unânimes quando referem de que modo os usuários participam do programa. Observamos que o vínculo desses com o PSF seestabelecea partir deuma demanda por saúde, mais precisamente em oposição à doença. Se, por um lado, os usuários adotam esse comportamento, os profissionais, por sua vez, corroboram com este modelo adotado, o que resta evidenciado na fala do profissional M édico 2.

A efetivação do Programa Saúde da Família passa tanto pela mudança de comportamento adotada pelos usuários diante o novo modelo, quanto pelo modo de agir dos profissionais de saúde para executar a proposta.

Para os usuários, a unidade básica de Saúde da Família continua sendo o antigo "postinho de saúde". As reivindicações desses ao programa são aumento demédicos especialistas, maisaparelhostecnológicos, maisremédios, mais agilidades nas ações. A perspectiva curativa está incutida na população e é reforçada na medida em que os médicos que atuam no programa são em sua maioria especialistas e não generalistas. Os usuários devem ser sensibilizados, informados eouvidos sobreas possibilidades de um sistema de participação e controle popular. Estas ideias devem ser difundidas paraque, a população mais conscientizada, secomprometa naturalmente com o programa ${ }^{14}$.

A filosofia do programa ressalta a importância das conexões entre saúde e cuidado de saúde para superar a hegemonia dos enfoques biomé dicos e criar e manter os enfoques primários como forma de melhorar as condições de saúde dos indivíduos em um ambiente saudável ${ }^{15}$. Compreender eincorporar esta filosofia deveser um propósito dos atores sociais que fazem 0 Programa Saúde da Família. Só assim, usuários e profissionais poderão avançar no sentido de concretizar a proposta.

Quanto à participação normativa, é possível afirmar que, no primeiro nível, a predominância do comportamento dos usuários tem enfoque na doença, no cuidado de si, com ênfase no tratamento e controle da evolução da doença, caracterizando 0 estágio de pré-contemplação.

Segundo nível: participação normativa

+ independência - contemplação

Este tipo de participação foi identificado nos depoimentos em que estavam presentes os descritores que expressam predominância nos temas sobre doença-saúde; cuidar de si; cuidar na família; prevenção.

$\mathrm{N}$ as falas que se seguem, percebemos 0 envolvimento do usuário com os problemas de saúde da família, bem como buscando a unidade de saúde não só mais pelo medicamento, mas já com uma mudança de comportamento para a prevenção dos agravos decorrentes das patologias instaladas.

Eu venho por causa do tratamento da doença do meu filho e também eu pego medicamento com a doutora ... [enfermeira] e pro problema da minha prevenção. (U-1.3)

U ma filha minha teve pneumonia e eu vim aqui, procurei 0 agente de saúde e vim aqui com ela e ela me levou à médica. (U-1.8)

A gente precisa ter cuidado com as crianças, começando pela boca. (U-3.1)

Eu venho aqui por causa de minha mãe, por que ela não pode caminhar, pra esse negócio de ol har a pressão. (U -4.4)

Eu trouxe meu marido, ele está com um problema, ele tem sangramento constante eestá precisando fazer um eletro. (U-5.7) 
Nas falas dos usuários, registramos práticas normativas, as quais apresentam uma certa independência de buscar por si só o serviço, incluindo o cuidar da família; no entanto, essa prática ainda permanece a partir da doença. Caracteriza-se pela necessidade percebida pelos usuários de que existe um problema, mesmo que ainda seja a doença. Há uma ambivalência quanto à perspectiva de mudança, caracterizando a fase de contemplação.

Os profissionais reforçam o evidenciado junto aos usuários, de modo que essas mudanças de comportamento podem ser confirmadas no estudo.

As pessoas que são cadastradas, que são hipertensos, diabético, hanseníase, eles sempre estão lá de oito em oito dias, de quinze em quinze dias, mesmo que não vá pegar o medicamento, mas vão verificar a pressão ou o exame da diabete, é assim de quinze em quinze dias. (ACS 3.1)

Eles procuram trazer os filhos aqui pra parte odontológica, sempre vem acompanhado. (Aux. Enf. 1)

Elas já chegam a falar do seu filho drogado, já chegam a comentar quando tem uma filha queestá bebendo. (Enfermeira 1)

A família sempre ajuda, principalmente na questão de horários do medicamento, a gente sempre diz "mostre isso aqui pra seu filho, ele vai explicar pro senhor direitinho". (Aux. Enf. 5)

Os depoimentos dos profissionais indicam mudanças no comportamento dos usuários; no entanto, confirma-se a não superação de ênfase na doença, bem como uma prevenção ainda voltada somente para o controle da patologia.

Assim, no segundo nível da participação do usuário no Programa Saúde da Família, evidenciamos que há um movimento de cuidado na família; todavia, na sua maioria, centrado na demanda da cura, tratamento e prevenção da doença, 0 estágio de contemplação.

Terceiro nível: participação emancipatória

- determinação/preparação

A participação emancipatóriafoi encontrada no estudo quando nos relatos dos usuários evidenciamos descritores com os temas saúde-doença, cuidar de si; cuidar na família; prevenção; cuidar do entorno.

Registramos nos depoimentos dos usuários elementos que evidenciaram uma participação emancipatória, do tipo determinação ou preparação. Destacou-se principalmente a ação desses na família ena comunidade com enfoquena prevenção.
U ma das minhas vizinhas não estava ligando pra vacinar os filhos e sempre quando vem eu chamo edigo também a elas queébom, queevita doença. (U-1.2).

Eu tenho aprendido sobre higiene, como a gente cuidar do lixo pra que não atinja um vizinho da gente e nem atinja também a gente nem as pessoas que chega na nossa casa. M eus filhos só ia pro dentista se ficasse gritando "mãe meu dente está doendo" ehoje eu sempre levo elas pra tomar vacinas na época da vacina, levo elas na dentista também pra fazer revisão, pra aplicação do flúor epra fazer aquela limpeza pra tirar os tártaro e tanto levo meus filhos, como oriento pra levar minha neta. (U-1.4)

Eu faço um trabalho voluntário na creche, isto meajudou mais a conviver com as pessoas. (U-2.1)

Já encontrei várias mulheres aqui mesmo, da minha idadeou maisnova, quejá falaram pra mim que tem vergonha de fazer 0 exame de prevenção, então eu oriento, "não é assim, não é um bicho de sete cabeças, é muito bom prevenir". Eu fiz prevenção aqui, gostei, fui bem atendida. (U-2.2)

$\mathrm{N}$ as falas dos usuários, percebemos uma mudança de comportamento, ampliando o cuidado para a família e o entorno, bem como um enfoque na prevenção. Podemos considerar que já existe um comprometimento do usuário para mudar, quando expressou a vontade de servir à comunidade, bem como refereo seu envolvimento em atividades desenvolvidas pela ESF.

Os profissionais da ESF referem iniciativas desenvolvidas no cotidiano do programa que retratam uma participação emancipatória.

Já reunimos os alunos, nós reunimos e fizemos desses alunos os vigilantes em saúde, eles vão ser repassadoresna campanha da dengue. ( $M$ édico 01)

Eles [comunidade] têm uma dança folclórica, a dança do coco, trabalham direto na comunidade, ajudam a divulgar as coisas, são envolvidos com o posto. (Aux. Enf. 1)

Tem idosos que moram sozinhos e os vizinhos olham eles, vem avisar que está acontecendo isso e isso, avisam a agente. (Enfermeira 2)

Há muitas famílias que já estão com esse entendimento de buscar os seus direitos, de reivindicar, enquanto têm outras que só esperam. U masjá estão tentando buscar mais mel horias pras próprias comunidades, principalmente as que já estão organizadas com associações. (ACS 3.3)

Os profissionais trazem relatos que registram as mudanças ocorridas com os usuários no que se refere a uma visão ampliada para o cuidado na família e na comunidade. No terceiro nível de participação do usuário no Programa Saúde da Família, predominam ações direcionadas para 
prevenção na família e no entorno, o estágio de determinação/preparação.

Quarto nível: participação transformadora

- ação/manutenção

A participação transformadora do usuário dentro do Programa Saúde da Família foi evidenciada quando nos seus discursos identificamos descritores com os temas saúde-doença; cuidar desi; cuidar na família; prevenção; cuidar do entorno; políticas públicas; controle social.

Este tipo de participação no programa foi registrado quando nas falas os usuários referiram envolvimento com os problemas que afe tam a comunidade, buscando os segmentos responsáveis na tentativa de solucioná-los.

Depois veio essa outra equipenova eeu fui umas três vezes pra conseguir uma ficha e não consegui, fui conseguir em outro posto, quando eu chegava lá dizia que não tinha ficha ou a ficha já tinha dado toda ontem, marcamos uma reunião com o secretário de saúde e conversamos com ele. (U-1.4)

0 que eu aprendo, passo pra comunidade, pra meus vizinhos, eu não me reúno só aqui não, tem outras comunidades também que eu me reúno. (U-1.4)

Eu tive uma necessidade e procurei a vigilância sanitária eaté hoje eu estou esperando por essa equipe ejá tem mais de um ano. (U-1.4)

Eu procuro conscientizar algumas pessoas da importância de participar dessas reuniões, eu acho que deveria haver conscientização da necessidade de se envolver. (U-1.9)

Estas falas trazem uma mudança no comportamento do usuário, no sentido de envolvimento com os problemas da comunidade, bem como de articulação com outros segmentos da sociedade, buscando parcerias e troca de experiências. Consideramos, portanto, que, apesar de ser num contingente menor, ou seja, evidenciada em poucos relatos dos usuários, a participação transformadora está sendo constituída. Já acontece a ação para a mudança.

Vázquez et al. ${ }^{11}$ também observaram a ideia de organização emovimento social reivindicativo junto aos usuários de seu estudo, quando muitas vezes assumem o papel de canalizador dos anseios da comunidade. Os autores, porém, destacam que, quando se refere aos líderes comunitários, a participação tem ideia mais elaborada. Para eles, se caracteriza como um processo social dinâmico. Há um entendimento do processo como estratégia de integração da população em atividades associativas em busca demelhorias das condições desaúde, as organizações comunitárias monitoram 0 aten- dimento, a partir das queixas dos usuários levadas às organizações comunitárias, e estas atuam como interlocutor junto ao poder público no encaminhamento das reivindicações populares.

Entendemos que o comportamento adotado pelos informantes, tanto no estudo de Vázquez et al. como neste, se caracteriza um exercício da cidadania. 0 reconhecimento da cidadania por parte dos indivíduos é apontado como um dos fatores fundamentais para que se efetive a participação social no setor saúde ${ }^{16}$.

Os profissionais também reforçam estetipo de participação, conforme os depoimentos a seguir:

Antes da minha chegada aqui, o pessoal estava sem médico e eles foram à rádio, reivindicaram 0 médico pra cá porque eles estavam realmente precisando, quando eu cheguei a demanda era enorme, enorme, então eles participam. Foram até na secretaria e fizeram o comunicado. (M édico 1)

Q uando eu cheguei aqui, eu senti queeles sabiam se mobilizar, toda semana tinha uma denúncia na rádio quea gente estava sem médico e principalmente por questão política. Existem esses grupos, eles se organizam, vai atrás deajudar, não tem nem um mês que tinha um senhor precisando de uma cadeira de roda e aí elas se reúnem, vai atrás, vai na secretaria e até às vezes eu nem fico sabendo. (Enfermeira 1)

Os profissionais anunciam, nas suas falas, mesmo que de modo tímido, mudanças para uma participação do tipo transformadora ou a ação autônoma por parte dos usuários para buscar as mudanças, quando referem experiências de envolvimento desses com os problemas da comunidade, no sentido de solucionar as questões de interesse de toda uma coletividade. N este sentido, há por parte do usuário uma tomada de decisão para mudar, quando assumiu uma atitude diante da situação vivenciada.

A plicando a escala de Arstein como referência, as mudanças identificadas no usuário, que caracterizam o quarto nível deste estudo, podem ser atribuídas ao que 0 autor denomina de segundo nível de sua escala, chamada de "controle cidadão"12. Neste nível, a participação se expressa como o exercício de poder decisório, solidário e compartilhado ${ }^{17}$.

Considera-se que, à medida que se avança nesta escala, o processo participativo se torna mais complexo eexigente, visto queimplica, para o participante, o cumprimento de uma série de condições, dentreelas, conhecimentos, experiências, autonomia e consciência de interesses ${ }^{18}$.

A população éhistoricamente constituída dos "silenciados", quer seja pela injustiça, desigual- 
dade ou exclusão social a que estão submetidos. Exercitar nesses a participação éuma prática que envolve aprendizagem e formação de habilidades para cuidar de si, da família e da comunidade. Acreditamos que assim ocorrerá a manutenção da mudança, quando os usuários desejarem e perceberem os benefícios desta para suas vidas.

Evidenciamos o quarto nível da participação do usuário no Programa Saúde da Família. De modo incipiente, há um comportamento do usuário em direção à autonomia e emancipação para a promoção da saúde, o estágio de ação/ manutenção.

\section{Consideraçõesfinais}

Ao longo dos dez anos de implantação do Programa Saúde da Família, o estudo identificou o curso da mudança de comportamento dos usuários para cuidar de si, cuidar da família e cuidar do entorno.

Evidenciamos que, no primeiro nível, a ênfase foi na doença, especificamente na de si próprio. No segundo nível, registramos um cuidado na família, mesmo que ainda centrado na demanda da cura e tratamento da doença. No terceiro nível, avançou no sentido da prevenção na família, já com registros de olhar no entorno. No quarto nível, mesmo que timidamente, já se registra um comportamento do usuário para alcançar sua autonomia e emancipação.

Embora neste estudo a participação, para a maioria dos usuários, esteja longe de ser considerada como transformação social, os resultados encontrados parecem indicar um movimento ascendente de participação do usuário no Programa Saúde da Família em direção à promoção da saúde.

Percebemos que a aprendizagem em saúde ocorreu nos quatro níveis de participação, embora com limitações, mas o modelo aponta uma direção de aprendizagem euma prática de transformação deatenção à saúde. Se, porém, o quese pretendeéa participação da população, mais pre cisamente a participação do usuário na tomada de decisão dentro do Saúde da Família, para a concretização de todo um projeto maior, que éo da promoção da saúde, será necessário um esforço conjunto de toda a ESF, bem como dos gestores, num amplo plano de educação em saúde, orientado para despertar nas pessoas habilidades para o cuidado de si, da família e da comunidade. Neste sentido, torna-se necessário uma mudança de atitude e val ores daqueles que trabalham nos serviços, estimulando o usuário a conhecer efetivamente o contexto da saúde, relacionando-o aos seus direitos, a partir de sua experiência vivenciada como cliente.

Entendemosqueo diálogo estabelecido entre ESF eusuários poderá ser um canal possível para a conquista da participação dentro do Programa Saúde da Família e, ainda, poderá ser capaz de reduzir assimetrias nesse cenário, capacitando o usuário no sentido de aproximá-lo do contexto do programa. Acreditamos que isto poderáresultar no fortalecimento deum trabal ho com a comunidade.

N esta direção, deixamos neste estudo alguns indicativos: que a participação deve ser estimulada em todo e qualquer momento do trabalho dos profissionais da equipedo PSF edeveser componente da prática dos profissionais, quer o indivíduo seja atendido na unidade básica de saúde, na comunidade ou em uma sessão educativa. $A$ participação deve ser implementada como categoria central na prática dos profissionais, visando à autonomia e à emancipação dos usuários. Da mesma forma, a educação em saúde deve está transversalizada no eixo da prática desses profissionais, sendo um veículo para estimular a participação e mudanças comportamentais. Assim, participação eeducação em saúde constituem atividades intrínsecas do processo de trabalho dos profissionais, que devem conduzir a promoção da saúde do usuário, família e comunidade.

A Figura 2 sumariza os níveis da participação habilitadora, indicando a participação do usuário no Programa Saúde da Família. 


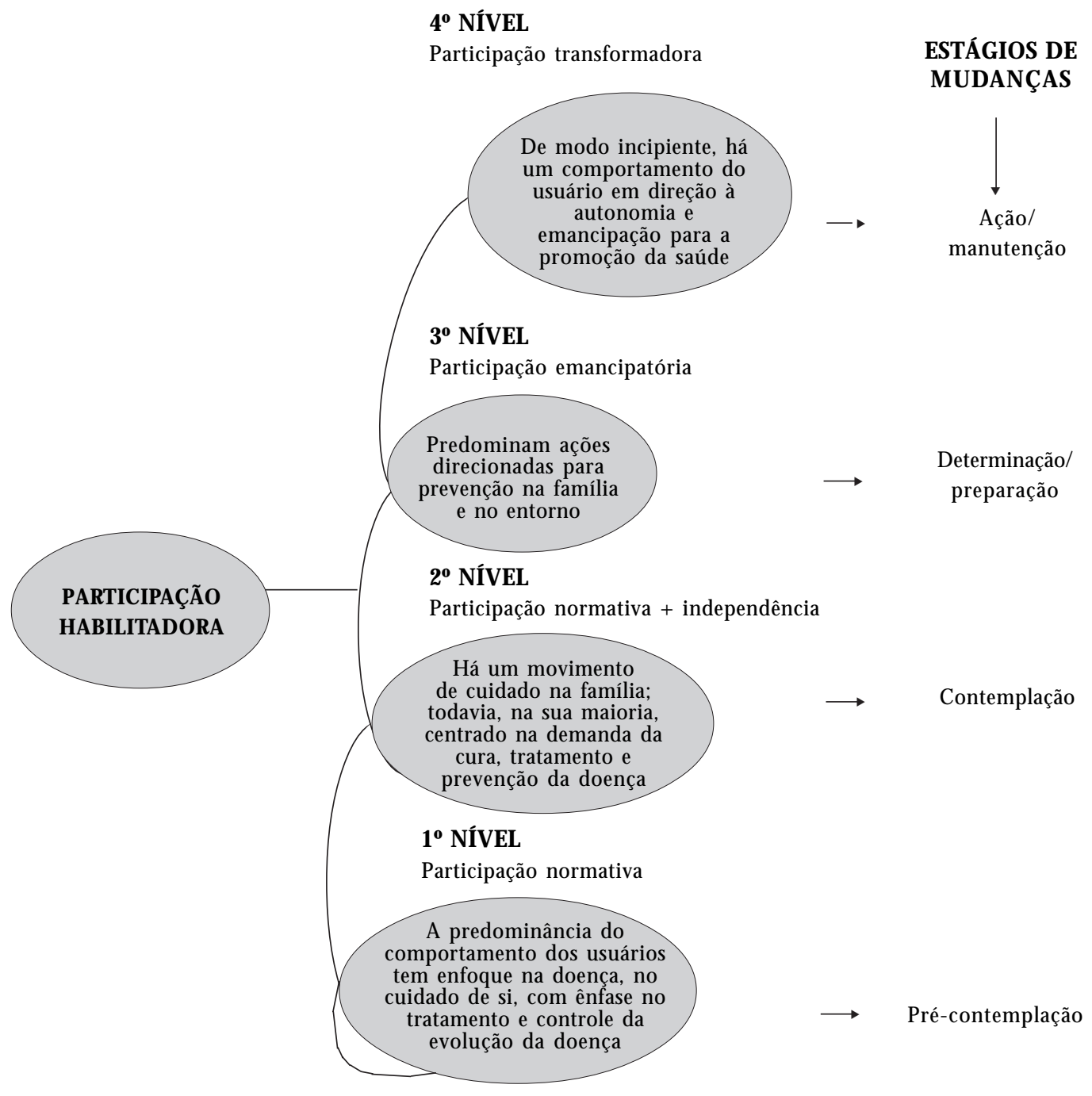

Figura 2. A participação habilitadora do usuário no Programa Saúde da Família. Crato (CE), 2006. 


\section{Colaboradores}

M FAS M achado participou da construção e de senvolvimento da pesquisa e redação do artigo; NFC Viera participou da construção e desenvolvimento da pesquisa e redação do artigo; RM Silva participou da sistematização, análise e síntese dos dados e da redação do artigo.

\section{Referências}

1. Mello DA, Rouquayrol MZ, Araújo D, Amadei M Souza J, Bento LF, Gondin J, Nascimento J. Promoção à saúde e educação: diagnóstico de saneamento da pesquisa participante articulada à educação popular (Distrito São João dos Queiroz, Quixadá, Ceará, Brasil).Cad Saude Publica [periódico na Internet] 1998; [acessado 2003 abr 13];14(3):[cerca de 13 p.]. Disponível em: http://www.bvsde.paho.org/ bvsasv/fulltext/mello.pdf

2. Brasil. M inistério da Saúde. Promoção da saúde: Carta de Ottawa, Declaração de Adelaide, D eclaração de Sunsvall, Declaração de Jacarta, D eclaração de Bogotá. Brasília: M inistério da Saúde; 2001.

3. Sousa M F, Hamann EM. Programa saúde da família no Brasil: uma agenda incompleta? Cien Saude Colet [periódico na Internet] 2008 [acessado 2007 mar 21];14(1):[cerca de 15 p.]. Disponível em: http:/ /www.scielosp.org/pdf/csc/v14s1/a02v14s1.pdf

4. Heimann LS, Mendonça M H. A trajetória da atenção básica em saúde e do programa saúde da família no SUS: uma busca de identidade. In: Lima NT, Cerschman S, Edler FC, Suárez JM, organizadores. Saúde e Democracia: histórias e perspectivas do SUS. Rio de Janeiro: Fiocruz; 2005. p. 481-502.

5. Araújo MRN, Assunção RS. A atuação do agente comunitário de saúde na promoção da saúde e na prevenção de doenças. Rev Bras Enferm 2004; 57(1):19-25.

6. Nutbean D, Harris E. Theory in a nutshell: a practitioner's guide to commonly used theories and models in health promotion. Sydney: University of Sydney; 1998.

7. Bunton R, Macdonald G. Health promotion. New York: Routledge; 1992.

8. Naidoo J, Wills J. Health promotion - foundations for practice. London: Baillière Tindal/ Royal College of Nursing; 1994.

9. Prochaska JO, DiClemente C. Transtheorical therapy: toward a more integrative model of change. Psycotherapy: theory, research e practice 1982; 20:161-173.
10. Brasil. Conselho Nacional de Saúde. Resolução nº 196/96. Decreto no 93.993, de janeiro de 1987. Estabelece critério sobre pesquisas envolvendo seres humanos. Bioética 1996; 4(2):15-25.

11. Vázquez ML, Silva M RF, Campos ES, Arruda IKG, Diniz AS, Veras IL, Pereira APC. Participação social nos serviços de saúde: concepções dos usuários e líderes comunitários em dois municípios do Nordeste do Brasil. Cad Saude Publica 2003; 19(2):579-591.

12. Arstein SR. A ladder of participation. American Institute of Planners Journal 1969; 35:216-224.

13. Bosi MLM, Affonso KC. Cidadania, participação e saúde: com a palavra, o usuário da rede pública de serviços. Cad Saude Publica 1998; 14:355-365.

14. Bettiol LM. Saúde e participação popular em questão: 0 Programa Saúde da Família. São Paulo: UNESP; 2006.

15. Pereira CMO, Alves MA. participação do enfermeiro na implantação do Programa Saúde da Família em Belo Horizonte. Rev Bras Enferm 2004; 57(3):311315.

16. Zakus D, Lysack C. Revisiting community participation. Health Policy and Planning 1998; 13:1-12.

17. Vázquez ML. Expresión de la participación social en los sistemas de salud de Latinoamérica. In: Foro Internacional. La Reforma del Sector Salud; 1999; Ciudad Guatemala. p. 255-261.

18. Gonzalez E. Manual sobre participación y organización para la gestión local. Cali: Ediciones Foro Nacional por Colômbia; 1996.

Artigo apresentado em 12/01/2008

Aprovado em 16/02/2008

Versão final apresentada em 29/10/2008 